\title{
Effectiveness and Safety of Tubeless Minimally Invasive Percutaneous Nephrolithotomy in Management of Lower Pole Renal Stones
}

\author{
MOHAMED ABD EL-WAHED, M.D.; AHMED M. SHOUMAN, M.D.; ASHRAF MOSHARAFA, M.D. and \\ AHMED A. MORSY, M.D.
}

The Department of Urology, Faculty of Medicine, Cairo University

\begin{abstract}
Background: Placement of a percutaneuos nephrostomy tube for drainage has been an integral part of the standard Percutaneous Nephrolithotomy (PNL) procedure. However, in recent years, the procedure has been modified to what has been called tubeless PNL, in which the nephrostomy tube is replaced with internal drainage by ureteral catheter or doubleJ stent.
\end{abstract}

Aim of Study: This study aims to assess the safety, efficacy and complications of tubeless minimally invasive percutaneous nephrolithotomy (mini PNL) in lower calyceal stones.

Patients and Methods: Patients with lower calyceal stones $\leq 2 \mathrm{~cm}$ were enrolled and underwent tubeless mini PNL between February 2014 and January 2016 using a semi rigid ureteroscope through a 16 Fr sheath and holmium laser lithotripsy. Patients were considered stone free when no stones or residuals $<3 \mathrm{~mm}$ were found on plain X-ray UT or non contrast CT.

Result: Twenty four patients with mean age of $39.8 \pm 7.1$ years underwent mini PNL for lower calyceal stones ranging in size from $10-20 \mathrm{~mm}(15.47 \pm 3.04)$. A single tract was used (16Fr). All patients had a tubeless procedure. Mean hospital stay was $1.5 \pm 0.1$ days. Twenty patients $(83.4 \%)$ had no or mild post-operative pain that required no analgesia. Minor complications occurred in two patients $(8.3 \%)$ in the form of post-operative fever that was treated conservatively.

Conclusion: Tubeless PNL can be safe and effective procedure in selected patients (stone burden $<2 \mathrm{~cm}$, single tract access, no significant residual stones, no significant perforation, minimal bleeding, and no requirement for a secondary procedure), with the potential advantages of decreased post-operative pain, analgesia requirement, and hospital stay. Stone Free Rate (SFR) is comparable to PNL and is significantly better than SWL and RIRS.

Key Words: Stone - Tubeless - Lower calyx - Minimally invasive-Percutaneous - Nephrolithotomy.

Correspondence to: Dr. Mohamed Abd El-Wahed, E-Mail: dr m abdelwahed @hotmail.com

\section{Introduction}

ACCORDING to the updated European Association of Urology (EAU) guidelines, PNL is recommended as the therapy of choice for large renal calculi $(>20 \mathrm{~mm})$ and also for smaller stones $(10-$ $20 \mathrm{~mm}$ ) of the lower renal pole when unfavourable factors for SWL exist [1].

In order to decrease morbidity associated with larger instruments like blood loss, postoperative pain and potential renal damage, a modification of the technique of standard PNL has been developed. This is performed with a miniature endoscope via a small percutaneous tract (11-20F) and was named as minimally invasive PNL or mini-PNL or mini Perc. Helal et al., were the first to describe a technique for pediatric percutaneous nephrolithotomy performed on a 2-year-old premature female child with the use of instruments with smaller diameters [2].

Previously it was thought that nephrostomy tubes provide hemostasis along the tract, avoid urinary extravasation, and maintain adequate drainage of the kidney [3]. However, based on the concept that the purpose of the tube is only to maintain adequate drainage of the kidney, a 'tubeless' approach has been developed by placing a ureteral stent or catheter to provide drainage after PCNL in lieu of a nephrostomy tube.

In 1997, Bellman and associates challenged the requirement for the routine placement of a nephrostomy tube after percutaneous renal surgery. Their 'tubeless' procedure involved the placement of an internal ureteral stent without any nephrostomy tubes. The study group consisted of 50 patients, who were compared with a control group 
of 50 patients undergoing percutaneous renal surgery with the standard nephrostomy tube. The hospitalization time, analgesia requirements, time to return to normal activities, and cost were significantly less with this new technique [4].

In this study, we assessed the safety, efficacy and outcome of tubeless mini-Perc in management of lower calyceal renal stones in an adult population.

\section{Patients and Methods}

This prospective non-randomized clinical trial was done in Kasr Al-Ainy Hospital between February 2014 and January 2016. Patients with stones located in the lower pole of the kidney either single or multiple stones with sum of $<2 \mathrm{~cm}$ in maximum diameter were included.

All patients were subjected to full history taking, physical examination, laboratory investigations [Complete Blood Count (CBC), coagulation profile, kidney function tests, liver function tests, random blood sugar, urine analysis and urine culture if needed] and imaging studies (abdomino-pelvic ultrasound, plain X-ray UT (KUB) and either intravenous urography or computed tomography of the urinary tract). A written informed consent was taken prior to surgery.

Data about stone site, size, shape and number were recorded. Operative time, size of tract, type of dilators used, type of lithotripter and intraoperative complications were collected.

Patients were asked to fast 6-8 hours before the operation. During induction with general anaesthesia a third-generation cephalosporin antibiotic was given after doing sensitivity test. Patients were positioned in lithotomy position on a fluoroscopy compatible operative table. Cystoscopy was done, and the ipsilateral ureteric orifice was identified, an open-tipped ureteric catheter (6 or 7Fr) was passed into the pelvicalyceal system over a hydrophilic straight tipped guide wire (0.038 inch). The ureteric catheter was secured to the Foley catheter. Once the ureteric catheter was fixed, the patient was placed in prone position. Bolsters were placed under the anaesthesiologist's supervision to facilitate ventilation and avoid dislodgment of the endotracheal tube. Patients were prepped with povidone iodine and sterile surgical drapes were used while making sure of easy access to the distal end of the ureteral catheter for contrast material injection.
A sterile drape was applied to the C-arm's receiver. Percutaneous access was obtained by the placement of an 18-gauge access needle into the lower calyx harbouring the stones under real-time $\mathrm{X}$-ray guidance. A $\mathbf{J}$ tipped curved guide wire (0.038 inch) was placed via the needle into the collecting system. A small incision was made with an 11-blade scalpel and the needle was removed.

Nephrostomy tract dilation was performed either using the first three Alken dilators or using Teflon Amplatz dilators up to $16 \mathrm{Fr}$ that can pass a $16 \mathrm{Fr}$ renal access sheath into the collecting system. We used a 9.5Fr ureteroscope (Wolf) through the renal access sheath. Fragmentation of the stones was done using Holmium laser lithotripsy. Stones were dusted with Holmium laser using low pulse energy and high frequency settings and most stone fragments could be flushed out along with the backflow through the sheath, while the remaining big fragments were extracted with stone forceps. All possible calyces were systematically inspected to evaluate for residual fragments. X-ray fluoroscopy was used at the end of the procedure to check for the presence of any residual fragments. At the end of the procedure, no nephrostomy tube was placed, and only the ureteral catheter was left.

Intraoperative complications including bleeding, parenchymal injury, extravasation, calyceal neck injury, stone migration, incomplete stone removal, adjacent organ injury and blood transfusion were also recorded.

Post-operative pain, fever, hematuria and extravasation were noticed and recorded. All patients had post-operative $\mathrm{CBC}$, serum creatinine and KUB on the first post-operative day. Data regarding the need for analgesia and hospital stay were recorded. Post-operative pain was assessed by $0-10$ Numeric Rating Scale for pain (Table 1).

Follow-up was done at one and three months postoperatively in the form of urinalysis, KUB and NCSCT. SFRs and the need for auxiliary procedures were reported at one and three months from the procedure.

Table (1): Numeric rating scale for pain.

\begin{tabular}{ll}
\hline 0 & No pain \\
\hline $1-3$ & $\begin{array}{r}\cdot \text { Mild pain (nagging, annoying, interfering little with } \\
\text { [ADLs]). }\end{array}$ \\
$4-6$ & $\cdot$ Moderate pain (interferes significantly with ADLs). \\
$7-10$ & Severe pain (disabling; unable toperform ADLs). \\
\hline
\end{tabular}

ADL: Activities of Daily Living 


\section{Results}

Twenty four patients were included in this study; twelve patients $(50 \%)$ were males and twelve patients (50\%) were females. Mean patients' age $( \pm \mathrm{SD})$ was $39.8( \pm 7.1)$ years.

Fourteen patients (58.3\%) had a history of failed SWL on the same existing stones. Six patients (25\%) had a history of stone surgery (either pyelolithotomy or PCNL) on the same side of the existing stone.

The mean preoperative Haemoglobin $(\mathrm{Hb})$ was $12.7 \pm 1.4 \mathrm{~g} / \mathrm{dl}$, the mean preoperative creatinine was $1.02 \pm 0.28 \mathrm{mg} / \mathrm{dl}$. Twenty patients $(83.4 \%)$ had a single stone, three patients (12.5\%) had two stones, while one patient $(4.1 \%)$ had three stones. Stone size ranged from 10 to $20 \mathrm{~mm}$ in maximal diameter with mean of $15.47 \pm 3.04 \mathrm{~mm}$ (in case of multiple stones the whole stone burden was $20 \mathrm{~mm}$ or less).

Mean operative time was $49.3 \pm 19.7$ minutes starting from ureteric catheter insertion till end of procedure. Alken dilators were used in 20 patients (83.4\%) while Amplatz dilators were used in 4 patients (16.6\%). All patients had laser fragmentation of the stones through a $16 \mathrm{Fr}$. sheath.

None of our patients developed intra operative bleeding, adjacent organ injury, calyceal neck injury, stone migration or sepsis.

The mean post-operative $\mathrm{Hb}$ was $12.1 \pm 1.1 \mathrm{~g} / \mathrm{dl}$. The mean post-operative creatinine was $1.04 \pm 0.2$ $\mathrm{mg} / \mathrm{dl}$. Post-operative fever occurred in two patients $(8.2 \%)$ and was treated conservatively. None of our patients required postoperative blood transfusion or suffered leakage from PNL site. Three patients (12.5\%) had no pain (score 0), 19 patients (79.2\%) had mild pain (score 1-3), 2 patients $(8.3 \%)$ had moderate pain (score 4-7) and none of our patients had severe pain (score 7-10). Post-operative analgesia (in the form of NSAID's) was given in four patients $(16.6 \%)$ while 20 patients $(83.4 \%)$ required no analgesia.

Mild post-operative hematuria occurred in twenty one patients $(87.5 \%)$ managed conservatively with IV fluids while three patients (12.5\%) had no gross hematuria [gross hematuria was classified based on colour into mild (rose), moderate (dark red), severe (dark red with blood clots)]. The mean hospital stay was $1.5 \pm 0.1$ days. Twelve patients $(50 \%)$ were discharged during the first postoperative day, while the other half were discharged on the second day after control of fever or improvement of hematuria.
Twenty-three patients $(95.9 \%)$ were stone free by KUB on the first post-operative day while one patient $(4.1 \%)$ had a residual stone $(4 \mathrm{~mm})$ which required post-operative SWL. After 3 months, all patients were stone free based on KUB findings.

\section{Discussion}

For the treatment of lower calyceal stones, it is still debatable which procedure is more appropriate in its management [5] as different procedures are available for the management including SWL, RIRS and PNL. Mini PNL offers an accepted alternative management option, as SWL often leads to persistent residual stone fragments, whereas conventional PNL achieves a higher stone-free rate and allows a shorter treatment period but with a somewhat higher surgical risk [6]. RIRS is accepted for the treatment of moderate sized stones with an excellent SFR while avoiding the morbid complications of PNL [7].

Several studies had found tubeless PNL to be effective and safe with low morbidity that provides satisfactory results in selected cases [8,9]. In most studies, inclusion criteria for this technique were a single puncture tract, procedure lasting less than $2 \mathrm{~h}$, less than three stones with a diameter $<25 \mathrm{~mm}$, complete extraction of all stones, and no significant bleeding at the end of the operation.

Different tract sizes were reported in the literature together with different techniques for tract dilatation and stone disintegration. Mishra et al., reported a tract size of $14 \mathrm{~F}-18 \mathrm{~F}$. Using fascial dilators in a stepwise manner. Nephroscopy was done by miniature nephroscope $(12 / 14 \mathrm{~F})$ together with holmium laser in 19 cases $(70.4 \%)$, lithovac in 6 cases $(22.2 \%)$ and ultrasonic lithotripter in 2 cases (7.4\%) [10] . Akbulut et al., used Amplatz dilators up to $18 \mathrm{Fr}$ in all patients followed by nephroscopy with $17 \mathrm{Fr}$. nephroscope together with Laser, pneumatic or ultrasonic lithotripter for stone fragmentation [11]. We used the Alken or Amplatz dilators to dilate a $16 \mathrm{~F}$ tract. Nephroscopy was done with a 9.5Fr ureteroscope and holmium laser for stone disintegration.

Mean operative time was comparable to other studies with a mean of $49.3 \pm 19.7$ minutes in our study while it was $61 \pm 1.3$ minutes in Kumar et al., study [12] and 45.2 \pm 12.6 minutes in Mishra et al., study [10] but this was shorter than other studies like Akbulut et al., the mean operative time was $91.9 \pm 37.6$ minutes [11]

Our center had previously reported a large series of tubeless PNL; Abou-Elela et al., [13] studied the 
safety and efficacy of tubeless PNL in a total of 128 patients from May 2001 to May 2004. The stone sizes ranged from 2 to $7 \mathrm{~cm}$ with a mean of $4.1 \mathrm{~cm}$ and they concluded that tubeless PNL with an externalized ureteral catheter is a safe procedure that is suitable for any patient who can be rendered stone free with a single procedure regardless of the initial stone burden [13]

We had minor complications in two patients (8.3\%) who had post-operative fever, none of our patients had significant bleeding which required blood transfusion. This was comparable to Mishra et al where complications occurred in three patients (11.1\%) [two patients $(7.4 \%)$ had fever and one patient $(3.7 \%)$ had pelvic perforation] [10], but lower than other studies like Kumar et al., where complications occurred in ten patients $(24.3 \%)$ [four patients $(9.7 \%)$ had severe pain, four patients $(9.7 \%)$ had severe hematuria and two patients (4.9\%) had fever] [12]. Akbulut et al., reported complications in 9 patients $(29 \%)$; 6 patients $(19.4 \%)$ had urine leakage from nephrostomy site due to obstruction of the ureter by stone fragments and needed DJ fixation and 3 patients $(9.6 \%)$ had fever) [11]

To our knowledge, this is the only study that used 0-10 numeric rating scale for pain assessment so we were able to assess post-operative pain following tubeless mini PNL more accurately and objectively.

Mean hospital stay was $1.5 \pm 0.1$ days which was shorter than many other studies like Akbulut et al., where the mean hospital stay was $2.7 \pm 1.6$ days [11], Kumar et al., 3.1 days [12] and Mishra et al., 3.2 \pm 0.8 days. [10] Mostly this was due to tubeless procedures and the relatively low complications. This may highlight the value of tubeless procedure being associated with less post-operative pain and shortened hospital stay.

We reported a Stone Free Rate (SFR) of (95.9\%), this was higher than some studies like Akbulut et al., where the SFR was $(90.3 \%)$ and Nagele et al., where the SFR was $(92.9 \%) \quad[11,6]$ and comparable to other studies like Kumar et al., where the SFR was (95.1\%) and Mishra et al where the SFR was $(96 \%)[\mathbf{1 2 , 1 0 ]}$.

Points of strength in our study include the design being a prospective study and the accurate assessment for pain and need for analgesia following surgery using 0-10 numeric rating scale for pain that is lacking in most of studies [10-12]
The main limitations in our study are the small sample size which limits statistical power and the fact that it is a single arm (non-comparative) study. We did not have adequate data regarding the stone composition, which could affect the surgical results.

\section{Conclusion:}

Tubeless PNL can be a safe and effective procedure in selected patients (stone burden $<2 \mathrm{~cm}$, single tract access, no significant residual stones, no significant perforation, minimal bleeding, and no requirement for a secondary procedure), with the potential advantages of decreased post-operative pain, analgesia requirement, and hospital stay.

The combination of using the mini PNL technique with Holmium laser lithotripsy is very helpful in decreasing intra renal manipulations and thus decreasing the chance for subsequent injuries and help the decision of a tubeless procedure.

Conflict of interest: None.

\section{References}

1- TÜRK C., KNOLL T., PETRIK A., SARICA K., et al: Guidelines on Urolithiasis. Arnhem (The Netherlands): European Association of Urology (EAU), 2013.

2- HELAL M., BLACK T., LOCKHART J., et al.: The Hickman peel-away sheath: Alternative for pediatric percutaneous nephrolithotomy. J. Endourol., 11: 171-2, 1997.

3- WINFIELD H.N., WEYMAN P. and CLAYMANRV: Percutaneous nephrostolithotomy: Complications of premature nephrostomy tube removal. J. Urol., 136: 77-9, 1986.

4- BELLMAN G.C., DAVIDOFF R., CANDELA J., GERSPACH J., et al.: Tubeless percutaneous renal surgery. J. Urol., 157: 1578-82, 1997.

5- TÜRK C., PETRIK A., SARICA K., SEITZ C., et al.: EAU Guidelines on Interventional Treatment for Urolithiasis. Eur. Urol., 69: 475-82, 2016.

6- NAGELE U., SCHILLING, SIEVERT K.D., et al.: Management of lower-pole stones of 0.8 to $1.5 \mathrm{~cm}$ maximal diameter by the minimally invasive percutaneous approach. J. Endourol., 22: 1851-3, 2008.

7- HUSSAIN M., ACHER P., PENEV B., et al.: Redefining the limits of flexible ureterorenoscopy. J. Endourol., 25: 45, 2011.

8- MOURACADE P., SPIE R., LANG H., JACQMIN D., et al.: 'Tubeless' percutaneous nephrolithotomy: Serieso f37cases. Prog. Urol., 17: 1351-4, 2007.

9- SHAH H., KHANDKAR A., SODHA H., KHARODAWALA S., et al.: Tubeless percutaneous nephrolithotomy: 3 years of experience with 454 patients. BJU. Int., 104: 840-6, 2009.

10- MISHRA S., SHARMA R., GARG C., et al.: Prospective comparative study of miniperc and standard PNL for 
treatment of 1 to $2 \mathrm{~cm}$ size renal stone. B.J.U. Int., 108 896-9, 2011.

11- AKBULUT F., KUCUKTOPCU O., KANDEMIR E., et al.: Comparison of flexible ureterorenoscopy and minipercutaneous nephrolithotomy in treatment of lower calyceal stones smaller than 2cm, Renal Failure, 38: 1, 163-7, 2016.

12- KUMAR A., KUMAR N., VASUDEVA P., et al.: A Pro- spective, Randomized Comparison of Shock Wave Lithotripsy, Retrograde Intrarenal Surgery and Miniperc for Treatment of 1 to $2 \mathrm{~cm}$ Radiolucent Lower Calyceal Renal Calculi: A Single Center Experience. J. Urol., 193: 1604, 2014.

13- ABOU-ELELAA, EMRAN A., MOHSEN M.A., REYAD I., et al.: Safety and efficacy of tubeless percutaneous renal surgery. J. Endourol., 2007.

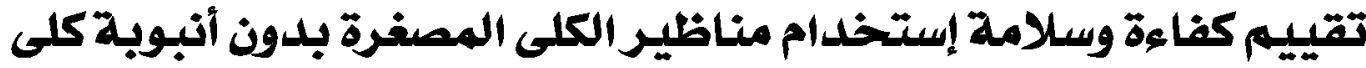

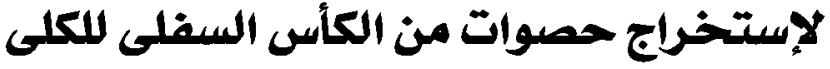

\author{
تهدف هذه الدراسة لتقييم كفاءة وبلامة إستخدام مناظير الكلى المصغرة بلون أنبوية كلى لإستخراج حصوات من الكأس السفلى للكلى.

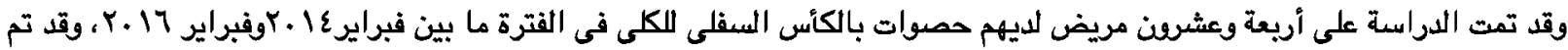

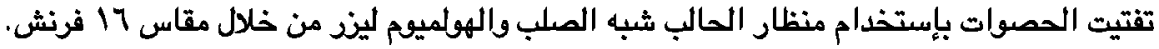

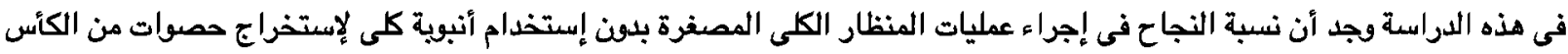 \\ السفلى اللكلى بلون وجود حصوات متبقية قد بلغ 90. 9. 9.

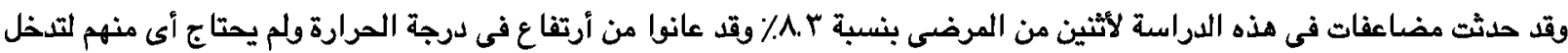 \\ جراحى. \\ وقد أثتت هذه الدراسة كفاءة وأمان إستخدام مناظير الكلى المصغرة بلون أنبوبة كلى لإستخراج حصوات من الكأس السفلى اللكى المرضى

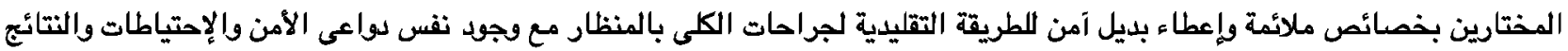

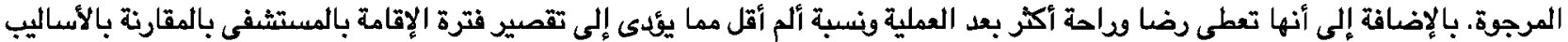 \\ التقليدية وهذا يؤدى إلى تقليل التكلفة الإجمالية المريضل التها.
}

